\title{
The Pathogenesis of Ossification of the Posterior Longitudinal Ligament
}

\author{
Liang Yan', Rui Gao², Yang Liu', Baorong He ${ }^{1}$, , Shemin $\mathrm{Lv}^{3}$, Dingjun Hao ${ }^{1, *}$ \\ ${ }^{1}$ Department of Spine Surgery, Hong Hui Hospital, Xi'an Jiaotong University College of Medicine, \\ Xi'an, 710054, China \\ ${ }^{2}$ Department of Respiration, The Children's Hospital of Xi'an City, Xi'an, 710054, China \\ ${ }^{3}$ Xi'an Jiaotong University College of Medicine, Xi'an, 710054, China
}

[Received December 9, 2016; Revised January 19, 2017; Accepted February 1, 2017]

\begin{abstract}
Ossification of the posterior longitudinal ligament (OPLL) is a multi-factorial disease involving an ectopic bone formation of spinal ligaments. It affects 0.8-3.0\% aging Asian and 0.1-1.7\% aging European Caucasian. The ossified ligament compresses nerve roots in the spinal cord and causes serious neurological problems such as myelopathy and radiculopathy. Research in understanding pathogenesis of OPLL over the past several decades have revealed many genetic and non-genetic factors contributing to the development and progress of OPLL. The characterizations of aberrant signaling of bone morphogenetic protein (BMP) and mitogen-activated protein kinases (MAPK), and the pathological phenotypes of OPLL-derived mesenchymal stem cells (MSCs) have provided new insights on the molecular mechanisms underlying OPLL. This paper reviews the recent progress in understanding the pathophysiology of OPLL and proposes future research directions on OPLL.
\end{abstract}

Key words: Heterotopic ossification, OPLL, BMP, TGF- $\beta$, Mesenchymal stem cells, MAPK

Ossification of the posterior longitudinal ligament (OPLL) was first reported by Key in 1838 [1] and described in detail by Tsukimoto and colleagues in 1960 [2]. OPLL is a disorder characterized by progressive ectopic ossification of the posterior longitudinal ligament (PLL), with occurrence of $70 \%$ in cervical spine and $15 \%$ in thoracic vertebra as well as in lumbar vertebra [3-5]. The predominant site of OPLL is the cervical segments, with the most frequent level at C5 $[3,4,6]$. Four subtypes of ossification of PLL have been categorized: segmental; continuous; mixed; and localized, circumscribed, or bridged [7]. Patients with OPLL usually develop into various degrees of neurological symptoms from discomfort to severe myelopathy due to compression of the spinal cord and nerve roots by progressively calcified PLL. Epstein et. al. estimated that up to $25 \%$ patients with cervical myelopathy presenting OPLL [8]. The motility and life quality of patients are greatly affected by these symptoms.

Most of OPLLs occur after age 40, with an average onset age of 50 [9]. OPLL occurs predominantly in male, nearly twice as often as in female. The overall prevalence of OPLL is of $1.9-4.3 \%$ in Japanese, $0.8-3.0 \%$ in other southeast Asian and $0.1-1.7 \%$ in North American and Europeans, suggesting a sporadic distribution [10, 11]. A recent comprehensive study from 3,161 patients in North America showed that the OPLL prevalence is various among races: $1.3 \%$ in Caucasian Americans, $4.8 \%$ in

*Correspondence should be addressed to: Drs. Dingjun Hao and Baorong He, Hong Hui Hospital, Xi'an Jiaotong University College of Medicine, Xi'an, 710054, China. E-mail: haodingjunspine@sina.com or hebr888@sina.com

Copyright: ( 2017 Yan L, et al. This is an open-access article distributed under the terms of the Creative Commons Attribution License, which permits unrestricted use, distribution, and reproduction in any medium, provided the original author and source are credited. 
Asian Americans, 1.9\% in Hispanic Americans, 2.1\% in African Americans, and 3.2\% in Native Americans [12]. The prevalence of OPLL in a specific location has also been reported. For example, the prevalence of thoracic
OPLL (T-OPLL), mainly located at T3-T4 segments, is approximately $1.9 \%$ in Japanese, with the peak distribution of occurrence at the age of 60 years [13].

Table 1. Summary of OPLL susceptibility genes

\begin{tabular}{|c|c|c|}
\hline References & Gene & SNPs \\
\hline $\begin{array}{l}\text { [75] Nishimura et al, } 2012 \\
\text { [91] Jun and Kim, } 2012\end{array}$ & fibroblast growth factor (FGF) 2 & $\begin{array}{l}\text { rs1476217 } \\
\text { rs3747676 }\end{array}$ \\
\hline $\begin{array}{l}\text { [75] Nishimura et al, } 2012 \\
\text { [91] Jun and Kim, } 2012\end{array}$ & $\begin{array}{l}\text { fibroblast growth factor receptor } \\
\text { (FGFR) } 1\end{array}$ & rs13317 \\
\hline $\begin{array}{l}\text { [55] Yan et al, 2013 } \\
\text { [54] Wang et al, 2008a } \\
\text { [53] Wang et al, 2008b } \\
\text { [52] Li et al, 2014 } \\
\text { [35] Kim et al, 2014b }\end{array}$ & $\begin{array}{l}\text { bone morphogenetic protein } 2 \\
\text { (BMP2) }\end{array}$ & $\begin{array}{l}109 \mathrm{~T}>\mathrm{G} \\
570 \mathrm{~A}>\mathrm{T} \\
109 \mathrm{~T}>\mathrm{G} \\
\text { exon } 3(-726) \mathrm{T} / \mathrm{C} \\
\text { Ser37Ala }(\mathrm{T} / \mathrm{G}) \\
\text { Ser87Ser }(\mathrm{A} / \mathrm{G})\end{array}$ \\
\hline $\begin{array}{l}\text { [92] Meng et al, 2010 } \\
\text { [56] Ren et al, 2012a } \\
\text { [93] Furushima et al, } 2002\end{array}$ & $\begin{array}{l}\text { bone morphogenetic protein } 4 \\
\text { (BMP4) }\end{array}$ & $\begin{array}{l}\text { SNP8 }(C>T) \\
\text { rs } 17563 \\
\text { rs76335800 } \\
\text { rs } 17563\end{array}$ \\
\hline [57] Ren et al, 2012b & $\begin{array}{l}\text { bone morphogenetic protein } 9 \\
\text { (BMP9) }\end{array}$ & $\begin{array}{l}\text { rs7923671 } \\
\text { rs75024165 } \\
\text { rs34379100 }\end{array}$ \\
\hline [94] Chin et al, 2013a & $\begin{array}{l}\text { vitamin K epoxide reductase } \\
\text { complex subunit } 1 \text { (VKORC1) }\end{array}$ & $-1639 \mathrm{G}>\mathrm{A}$ \\
\hline $\begin{array}{l}\text { [45] Han et al, } 2013 \\
\text { [42] Kamiya et al, } 2001\end{array}$ & $\begin{array}{l}\text { transforming growth factor-beta1 } \\
\text { (TGF-beta1) }\end{array}$ & promoter region $(-509 \mathrm{C}>\mathrm{T})$ exon $1(869 \mathrm{~T}>\mathrm{C})$ \\
\hline $\begin{array}{l}\text { [30] He et al, 2013 } \\
\text { [95] Nakamura et al, } 1999 \\
\text { [28] Koshizuka et al, } 2002 \\
\text { [29] Tahara et al, 2005 }\end{array}$ & $\begin{array}{l}\text { ectonucleotide pyrophosphatase } \\
\text { phosphodiesterase } 1 \text { gene } \\
\text { (ENPP1) }\end{array}$ & $\begin{array}{l}\text { C973T } \\
\text { IVS15-14T } \\
\text { IVS20 } \\
\text { A533C } \\
\end{array}$ \\
\hline [46] Jekarl et al, 2013 & $\begin{array}{l}\text { transforming growth factor beta } \\
\text { receptor type } 2 \text { (TGFBR2) }\end{array}$ & $\begin{array}{l}455-4 \mathrm{~T}-->\mathrm{A} \\
571 \mathrm{G}-->\mathrm{A} \\
95-35 \mathrm{C}-->\mathrm{T} \text { in intron } 1 \\
\end{array}$ \\
\hline [38] Wei et al, 2014 & collagen 17A1 (COL17A1) & $\begin{array}{l}\text { rs805698 (c. G1282A, (p.G428S) } \\
\text { rs4918079 (c.C2595T, p. R865R) }\end{array}$ \\
\hline [38] Wei et al, 2014 & $\begin{array}{l}\text { Protein patched homolog } 1 \\
\text { (PTCH1) }\end{array}$ & $\begin{array}{l}\text { c.C3491T (p. P1164L) } \\
\text { c.C794G (p. T265S) } \\
\text { c.C3695T (p. P1232L) }\end{array}$ \\
\hline [96] Chon et al, 2014 & $\begin{array}{l}\text { BH3 interacting domain death } \\
\text { agonist (BID) }\end{array}$ & $\begin{array}{l}\text { rs8190315, Ser10Gly } \\
\text { rs2072392, Asp60Asp }\end{array}$ \\
\hline $\begin{array}{l}\text { [36] Kong et al, } 2007 \\
\text { [37] Tsukahara et al, } 2005 \\
\text { [35] Kim et al, 2014b } \\
\text { [20] Tanaka et al, 2003 }\end{array}$ & collagen 6A1 (COL6A1) & $\begin{array}{l}\text { promoter }(-572 \mathrm{~T}) \text {, intron } 32(-29) \text { and intron } 33 \\
(+20)\end{array}$ \\
\hline [31] Koga et al, 1998 & collagen 11A2 (COL11A2) & Intron $6(-4 \mathrm{~A})$ \\
\hline $\begin{array}{l}\text { [97] Kim et al, } 2011 \\
\text { [98] Guo et al, } 2014\end{array}$ & $\begin{array}{l}\text { interleukin } 15 \text { receptor, alpha } \\
\text { (IL15RA) }\end{array}$ & $\begin{array}{l}\text { rs2296139 } \\
\text { rs2228059 }\end{array}$ \\
\hline [99] Chung et al, 2011 & Toll-like receptor 5 (TLR5) & $\begin{array}{l}\text { rs5744168, } \\
\text { rs5744169, } \\
\text { rs2072493, } \\
\text { rs5744174 }\end{array}$ \\
\hline [100] Yan et al, 2010 & $20 \mathrm{p} 12$ & $\begin{array}{l}\operatorname{rs} 1116867(\mathrm{~A} / \mathrm{G}) \\
\mathrm{rs} 965291(\mathrm{G} / \mathrm{A})\end{array}$ \\
\hline [78] Liu et al, 2010 & $\begin{array}{l}\text { runt-related transcription factor } 2 \\
\text { (RUNX2) }\end{array}$ & $\begin{array}{l}\text { rs1321075 } \\
\text { rs12333172 }\end{array}$ \\
\hline
\end{tabular}




\begin{tabular}{|l|l|l|}
\hline [101] Kim et al, 2014a & $\begin{array}{l}\text { angiotensin I converting enzyme } \\
\text { (peptidyl-dipeptidase A) 1 (ACE) }\end{array}$ & insertion/deletion (I/D) polymorphism \\
\hline $\begin{array}{l}\text { [27] Horikoshi et al, 2006 } \\
\text { [102] Ogata et al, 2002 }\end{array}$ & Estrogen Receptor 1 (ESR1) & $\begin{array}{l}\text { rs934079 } \\
\text { rs222848 }\end{array}$ \\
\hline [103] Kim et al, 2012 & Estrogen Receptor 2 (ESR2) & rs1256049 \\
\hline [19] Matsunaga et al, 1999 & HLA haplotype & N.A. \\
\hline [27] Horikoshi et al, 2006 & $\begin{array}{l}\text { Alpha 2-Heremans-Schmid } \\
\text { glycoprotein (AHSG) }\end{array}$ & rs2077119 \\
\hline $\begin{array}{l}\text { [104] Numasawa et al, } \\
\text { 1999 }\end{array}$ & retinoic X receptor beta (RXRB) & $\begin{array}{l}\text { T-->A substitution at nucleotide +378 (nucleotide } \\
\text { numbering is from the start of exon 10) }\end{array}$ \\
$\begin{array}{l}\text { 3' end +140 (an A-->T substitution) and 3' end } \\
+561 \text { (a nucleotide insertion, C-->CC) } \\
\text { (numbering is from the end of exon 10) }\end{array}$ \\
\hline [102] Ogata et al, 2002 & interleukin 1 beta (IL-1 $\beta$ ) & N.A. \\
\hline [105] Kobashi et al, 2008 & vitamin D receptor (VDR) & N.A. \\
\hline [27] Horikoshi et al, 2006 & $\begin{array}{l}\text { transforming growth factor-beta3 } \\
\text { (TGF-beta3) }\end{array}$ & $\begin{array}{l}\text { rs226862 } \\
\text { rs22847 }\end{array}$ \\
\hline
\end{tabular}

OPLL can be a secondary complication in patients with several other diseases, such as hypohosphatemic rickets/osteomalacia, hypoparathyroidism and acromegaly/gigantism. Early-onset and severe OPLL usually occurs in these diseases $[14,15]$. Most OPLL cases are primary (idiopathic), which are discussed in this review below. In general, OPLL is considered a multifactorial disease with both environmental and genetic factors contributing to the development. The nongenetic factors for OPLL include age, diabetes mellitus, obesity, diet, exercise and mechanical stimulation $[14,16$, 17]. Plasma pentosidine levels, femoral neck bone mineral density (BMD) and diffuse idiopathic skeletal hyperostosis (DISH) are also associated with OPLL [11]. In this review, we focus on the genetic factors and signaling pathways contributing to the pathogenesis of OPLL.

\section{OPLL susceptibility loci}

OPLL has a strong genetic predisposition. Familial OPLL cases have been reported in both Asian and Caucasian. The associated genetic loci linked to OPLL susceptibility have been identified. For example Terayama et al have reported that the prevalence of OPLL is $26 \%$ in the parents and $29 \%$ in the siblings of probands from 347 OPLL families, which is significantly higher than that in the general population [18]. Matsunaga et al found that the prevalence of OPLL is higher in the sibs sharing identical human leukocyte antigen ( $H L A$ ) haplotypes from families of 24 OPLL patients. Later on, a non-parametric linkage analysis focusing on the HLA region revealed a significant linkage on D6S276 with OPLL [19]. Some candidate genes were identified around the marker, including collagen 11A2 (COL11A2) and retinoic $\mathrm{X}$ receptor beta $(R X R B)$. Another significant linkage is D21S1903 on 21q showing collagen 6A1 (COL6A1) as a potential genetic factor to OPLL [20].

A genome-wide linkage study using 214 affected Japanese sib-pairs suggested OPLL-associated loci with potential linkages at 1p21, 2p22-2p24, 7q22, 16q24 and $20 \mathrm{p} 12$ [21]. Furthermore, a genome-wide association study (GWAS) was performed in a total of 15,000 individuals, and six susceptibility loci for OPLL were identified: 20p12.3, 8q23.1, 12p11.22, 12p12.2, 8q23.3 and $6 \mathrm{p} 21.1$ [22]. The genes in or near associated regions include hydroxyacid oxidase 1 (HAOl), r-spondin 2(RSPO2), eukaryotic translation initiation factor 3E $(E I F 3 E)$, ER membrane protein complex subunit 2 (EMC2), coiled-coil domain containing 91 (CCDC91), radial spoke head protein 9 homolog (RSPH9) and serine/threonine kinase 38 like (STK38L) [22]. Further gene expression analysis showed HAO1, RSPO2 and CCDC91 had lower expression levels during early stages of chondrogenesis, while RSPH9 and STK38L showed increases in expression in osteoblasts. The authors suggested that RSPH9 and STK38L may participate in the membranous ossification process and HAO1, RSPO2 and CCDC91 play roles in the endochondral ossification process [22]. OPLL GWAS has provided essential information on chromosomal positions significantly associated with OPLL, which is far narrower than what have been defined by previous linkage studies. However, a gap between functional genomic positions and the causal genes of OPLL still needs to be bridged through more efficient target gene association studies.

\section{OPLL susceptibility genes and signaling}

Besides linkage studies and GWAS, many target gene association studies of OPLL have been carried out over the past several decades. Numerous genes, including 
cytokines and growth factors, have been revealed as potential factors that contribute to the pathophysiology of OPLL, which are listed in table 1 . Many candidates reside in the functional positions that have been defined by linage studies or GWAS above. In the meantime, in vitro and in vivo expression profile analysis has suggested multiple signaling pathways involved in the development and progression of OPLL, including transforming growth factor-beta (TGF- $\beta$ ), bone morphogenetic protein (BMP) and mechanical stress signaling. Here we focus on several major OPLL-associated candidate genes and their signaling pathways.

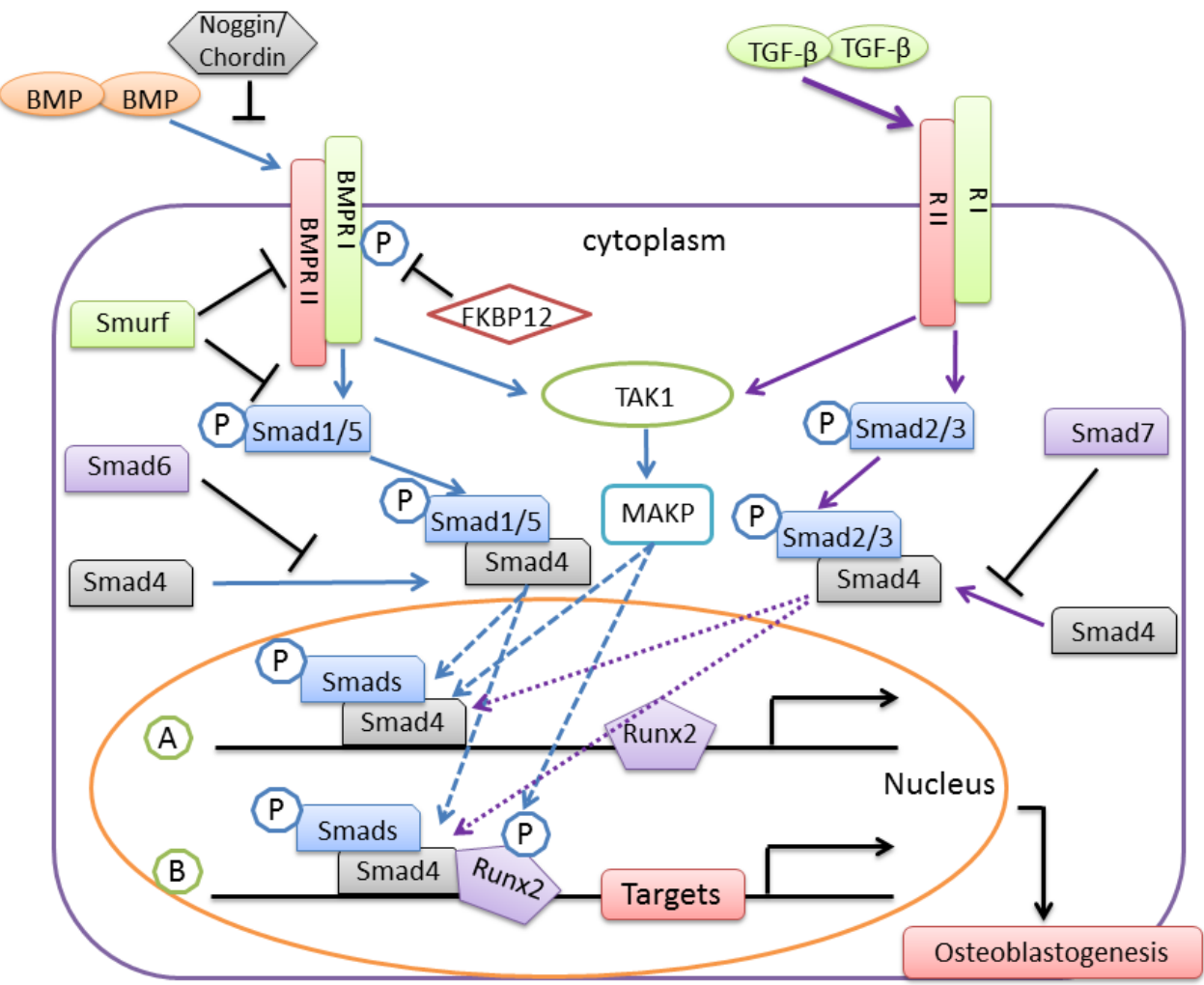

Figure 1. BMP/TGF- $\beta$ signaling and negative regulation in osteoblastogenesis. BMP or TGF- $\beta$ binds to and activates their receptor type II (RII) and receptor type I (RI) and leads to subsequent phosphorylation of Smads. Activated Smads form a complex with Smad4, translocate into the nucleus and trigger transcription of Runx2. Subsequently, Smads/Smad4 associate with Runx2 to regulate target genes necessary for osteoblastogenesis. BMP/TGF- $\beta$ signaling can also activate transforming growth factor beta-activated kinase 1 (TAK1) and result in activation of MAPK, leading to enhancement of Smads/Smad4 induced transcription. The negative regulations include prevention of activation of Smads by Smad6/7, inhibition of receptors activation by Smurf and FK506 binding protein 1A (FKBP12), and inhibition of BMPs binding to their receptors by Noggin/Chordin. P, phosphorylation.

\section{Ectonucleotide Pyrophosphatase/Phospho-} diesterase 1 (ENPP1): The tiptoe walking (twy) mice has a natural occurrence of pathological ossification of spinal ligaments, such as ossification of the posterior longitudinal ligament, enlargement of the nucleus pulposus, regenerative proliferation of annulus fibrosus cartilaginous tissues, and neovascularization and metaplasia of primitive mesenchymal cells to osteoblasts in the spinal ligaments $[23,24]$. ENPP1 was identified subsequently as the gene responsible for twy phenotypes, which was mutated and resulted in a stop codon in twy [25]. EPP1 is a type II transmembrane metalloenzyme and functions to regulate soft-tissue calcification and bone mineralization. It acts as a calcification inhibitor via the production of PPi [26]. Many studies have attempted to screen OPLL-associated single-nucleotide polymerphisms (SNPs) of ENPP1. So far four SNPs in ENPP1 have been found to be associated with either the 
development or the severity of OPLL in human. One is IVS15-14T, a $\mathrm{T} \rightarrow \mathrm{C}$ transition in intron 15 [27, 28], and the second is IVS20-dell11T, a $\mathrm{T}$ deletion at 11 nucleotides upstream of the splice acceptor site in intron 20 [29]. The remaining two involve in the coding region: $\mathrm{A} 533 \mathrm{C}$ is an $\mathrm{A}$ to $\mathrm{C}$ change in exon 4 that alters the protein sequence from $\mathrm{K}$ to $\mathrm{Q}$ and $\mathrm{C} 973 \mathrm{~T}$ is a $\mathrm{C}$ to $\mathrm{T}$ substitution in exon 9. Patients with the IVS20-dell11T or A533C have approximately 3 times greater chance of not having disease progression after surgery, a possible predictor for post-surgery outcome [30].

Collagen genes: Collagen participates in bone and cartilage formation and mediates the interaction between extracellular matrix components and cell surface proteins. Mutations and/or aberrant expressions of collagen genes may induce various pathological phenotypes in connective tissues. Many collagen genes are shown to be associated with OPLL, including COL11A2,[31-34] COL6A1 [20, 35-37] and collagen 17A1 (COL17A1) [38]. COL11A2 is the type XI collagen that associates with type II collagen, the main collagenous component of cartilage. COL11A2 has been found to be significantly linked to a predisposition to OPLL $[31,34]$. The retaining exon 7 together with removed exon 6 in intron $6(-4 \mathrm{~A})$ in $C O L 11 A 2$ is speculated to play a protective role in the ectopic ossification process $[32,33]$. Three different SNPs of COL6A1 have been found to be associated with OPLL: promoter $(-572 \mathrm{~T})$, intron $32(-29)$ and intron 33 (+20) [20, 35-37]. Wei et al have found two SNPs of COL17A1, rs805698 (c.G1282A, p.G428S) and rs4918079 (c.C2595T, p.R865R), are significantly associated with OPLL via a whole exome sequencing [38]. The specific roles of these SNPs of collagen genes in the pathogenesis of OPLL remain unclear, though their contributions to the formation of extracellular matrix scaffolds may facilitate endochondral ossification.

TGF- $\beta$ signaling and SNPs: The TGF- $\beta$ superfamily contains over forty members, including TGF$\beta s$, Nodal, Activin and BMPs [39]. TGF- $\beta /$ BMPs signaling and their cross-talk with signaling pathways of MAPK, Wnt, Hedgehog, Notch and FGF play very crucial roles in bone formation during mammalian development [39] (Fig. 1). TGF- $\beta$ is enriched in bone and cartilage that also contain a large number of target cells for TGF- $\beta$. TGF- $\beta$ is critical in maintaining and expanding mesenchymal stem cells (MCS) / progenitor cells and progenitors of osteoblasts via autocrine and paracrine stimulations $[39,40]$. Thus, the $T G F-\beta$ genes, specifically $T G F-\beta 1$, due to its importance in regulation of bone metabolism, are considered leading candidates in increasing individual susceptibility to OPLL [41-43]. TGF- $\beta$ is present in the ossified matrix and chondrocytes of adjacent cartilaginous areas of OPLL, but not in MSCs and non-ossified ligament, suggesting it may stimulate bone formation at a later stage of ectopic ossification [44].

The $869 \mathrm{~T}>\mathrm{C}$ polymorphism in exon 1 of the $T G F-\beta 1$ gene has been studied extensively regarding OPLL pathogenesis, but results are contradictory. Kamiya et al. have initially reported that SNP $869 \mathrm{~T}>\mathrm{C}$ is a genetic determinant of predisposition for cervical OPLL, with the $\mathrm{C}$ allele of $869 \mathrm{~T}>\mathrm{C}$ representing a risk factor for genetic susceptibility to OPLL [42]. However, other three studies found no significant association between SNP 869T $>\mathrm{C}$ and the prevalence of OPLL in larger-scale studies [27, 43, 45]. A further stratified analysis has shown patients with the $\mathrm{C}$ allele of $869 \mathrm{~T}>\mathrm{C}$ display OPLL more frequently in the cervical, thoracic, or lumbar spine [43]. In addition, the promoter region $-509 \mathrm{C}>\mathrm{T}$ polymorphism of $T G F-\beta 1$ doesn't show significant association with OPLL [45].

A large scale case-control study has shown $T G F-\beta 3$ polymorphisms of rs226862 and rs22847 are significantly associated with OPLL, among which the rs226862 polymorphism, residing deep within an intron without altering any known conserved transcription factorbinding motifs, shows the most significant association [27]. Three polymorphisms of the TGF- $\beta$ receptor 2 (TGFBR2) gene have been found associated with OPLL: 455-4T-->A, 571G-->A and 95-35C-->T [46]. The function of these SNPs remains unclear. Though the physiological function of TGF- $\beta$ indicates its potential role in the pathophysiology of OPLL, additional genetic and functional studies are necessary to reveal their roles.

BMP signaling and SNPs: As part of TGF- $\beta$ family, BMPs are the most critical growth factors that stimulate osteoblast and chondrocyte differentiation, resulting in bone and cartilage formation (Fig. 1). BMP-mediated Smad signaling plays a central role in regulating many transcriptional factors, such as Runx2, Osterix, Msx2, Dlx5/6 and Sox9 [47]. Genetic and biochemical studies indicate these transcriptional factors are essential for osteoblastogenesis and chondrogenesis [48]. The details of BMP-Smad signaling have been described in many excellent reviews [39, 49, 50]. Here we focus on the current understanding of the role of BMP signaling on OPLL pathogenesis.

Both BMP receptors and BMPs have aberrant expression patterns in OPLL tissues. BMP receptors have significant higher expression levels in the ossified ligament of OPLL than those in the non-OPLL tissue. In addition, the non-ossified segment of the PLL in OPLL specimens also expresses BMP receptors to a greater extent than that in the non-OPLL tissue [51]. BMP-2 is present in the ossified matrix and chondrocytes of adjacent cartilaginous areas of OPLL and in MSCs in the immediate vicinity of the cartilaginous areas [44]. These studies show that molecular alterations of BMP precede the development of OPLL, suggesting BMP may 
stimulate differentiation of mesenchymal progenitor cells and act as an initiating factor in the development of OPLL.

Many investigations have revealed the associations between BMP SNPs and OPLL. Several reports have showed that frequencies for the $\operatorname{rs} 2273073(\mathrm{~T} / \mathrm{G})$ and rs235768 (A/T) polymorphisms of $B M P 2$ are significant higher in the OPLL than those in control groups. Both SNPs are associated with the occurrence of OPLL in Chinese Han population [52-55]. The functional analysis of rs2273073 (T/G) SNP has showed this mutant aberrantly activates BMP-Smad signaling. For example, transfection of this $B M P 2$ mutant promotes the activation of p-Smad1/5/8, expression of Smad4 and activity of alkaline phosphatase (ALP) [55]. Uniaxial cyclic stretch promotes osteogenic differentiation and synthesis of BMP2 in the C3H10T1/2 Cells with $B M P 2$ gene variant of rs2273073 (T/G) [52]. However, Kim et al reported that both BMP2 SNPs showed no significant difference between OPLL and non-OPLL groups in Korean populations [35]. The diversities of these data may be resulted from variations of genetic background between these two populations. In addition, Lin's group has characterized a total of 18 BMP4 SNPs from 450 OPLL patients and 550 matched controls, and found that rs $17563(\mathrm{C} / \mathrm{T})$, rs76335800(A/T) and SNP8 (C>T) are the SNPs associated with increased genetic susceptibility to OPLL [56]. They also have showed that rs7923671 (T/C), rs $75024165(\mathrm{C} / \mathrm{T})$ and $\mathrm{rs} 34379100(\mathrm{~A} / \mathrm{C})$ of $B M P 9$ are associated with OPLL [57].

Mechanical stress signaling: Mechanical stretch has been considered as a factor contributing to the development and progression of OPLL [58]. Numerous genes have their expression levels upregulated in response to mechanical stress, such as ALP, BMP-2, BMP-4, BPM receptors, osteopontin, Cbfa1, Type I collagen, osteocalcin, integrin $\beta 1$, endothelin-1, etc $[16,59]$. Mechanical stress elevates prostacyclin synthesis in ligament cells derived from OPLL patients and induces osteogenic differentiation [60]. It also regulates P2Y1 purinoceptor subtypes expression in OPLL cells and promote OPLL progression [61].

In responding to environmental mechanical stress, multiple signaling pathways are involved, including MAPK. Activation of ERK, resulting from abnormal mechanical stress, can facilitate the development of OPLL. Mechanical stress up-regulates connexin 43 (Cx43) expression in ligament fibroblasts, leading to osteoblastic differentiation $[62,63]$. In a recent study, Chen et al have found $\mathrm{Cx} 43, \mathrm{p}$-ERK, p-p38 MAPK and p-JNK are upregulated in OPLL as compared to non-OPLL both in vivo and in vitro [64]. The activation of these signals by mechanical stress is dependent upon Cx43. Knock-down of $\mathrm{Cx} 43$ blocks the ERK1/2 and p38 MAPK pathways and reverses the osteogenic effect of mechanical stress on ligament fibroblasts. Therefore, $\mathrm{Cx} 43$ functions to promote the osteoblastic differentiation of ligament fibroblasts partly via the activation of ERK $1 / 2$ and p38 MAPK signals [64]. Another group has found that the cultured OPLL fibroblasts exhibit osteogenic characteristics and show increases in expressions of $p$ EKR, osteocalcin (OCN), ALP and collagen 1 (COL1) as compared to non-OPLL fibroblasts. Knockdown of EKR in OPLL fibroblasts inhibits expression of OCN, ALP and COL1, indicating that p-ERK-mediated ER stress might be involved in the development of OPLL [65].

Vimentin, a type III intermediate filament protein, is also involved in responding to mechanical stretch in OPLL cells. Overexpression of vimentin in osteoblasts results in decrease in ALP activity and expression of osteoblast markers, and delay of mineralization, leading to inhibition of osteoblast differentiation.[66] Expression of vimentin can be downregulated by mechanical stress, which leads to increase in expressions of OCN, ALP and COL 1 in OPLL cells. Thus vimentin may play an important role in the progression of OPLL through the induction of osteogenic differentiation in OPLL by its down-regulation [67].

Other potential pathways: A microarray study of 1536 genes in OPLL as compared to control showed wound healing is the most activated signaling occurred in OPLLs with the upregulations of platelet-derived growth factor-B (PDGFB) and peroxiredoxin 2 (PRDX2). The Toll-like receptor signaling pathway had the most significant changes in OPLL, with upregulations of some key members in Toll-like pathway such as Toll-like receptor 1 (TLR 1), TLR5, TLR7, and mitogen-activated protein kinases 10 (MAPK10) and phosphoinositide-3kinase (PI3K), regulatory subunit 1 (PIK3R1), suggesting the crucial roles of PI3K in the development of OPLL [68].

\section{MSCs and OPLL}

MSCs are multipotent progenitor cells that can differentiate into a variety of cell types, including osteoblasts and chondrocytes. MSCs have been reported to play important roles in pathogenic development of several ossification process, such as fibrodysplasia ossificans progressiva (FOP) [69], ectopic ossification following burn injury[70] and aortic valve calcification [71]. The initial attempt to isolate MSCs from human spinal ligaments was made by Asari et al. They found these MSCs have potentials to differentiate into osteogenic, adipogenic or chondrogenic cells with expressions of surface markers of CD34, 73, 90 and 105 but not CD45. They located in the collagenous matrix of the ligament and perivascular areas [72]. Further study showed that MSCs with perivascular residing expressed pericytes marker $\alpha$-smooth muscle actin ( $\alpha$-SMA) but not 
endothelial marker CD31, thus was a subpopulation of pericytes. This is coincident with the theory that a subset of pericytes was MSCs. The ossified ligamentum flavum (OLF) showed a significant higher quantity of MSCs around blood vessels and within collagenous matrix as compared to non-OLF samples [73]. OPLL-derived MSCs showed significantly higher osteogenic differentiation potential and in vitro increases in activity of ALP and expressions of BMP2, runt-related transcription factor 2 (Runx2) and ALP than those from non-OPLL patients. The author suggested that an upregulation of osteogenic differentiation potential of OPLL-derived MSCs could be a causal factor to the ossification in spinal ligaments [74].

Many transcriptional factors regulate osteogenesis and chondrogenesis from MSCs, among which Msx2, Sox9, Runx 2 and Osterix are the central components for bone and cartilage development [75]. As a key player in osteoblast differentiation, Runx 2 regulates expressions of all major osteoblasts-specific genes, including ALP, type I collagen, osteopontin and OCN, via binding to the osteoblast-specific cis-acting element 2 in their promoters. Runx 2 have been shown to be linked to OPLL by many lines of evidence. Runx 2 expression in OPLL cells is significantly higher than that in non-OPLL [16]. Inhibition of both Runx2 and angiopoietin-1, a downstream of Runx2 in OPLL cells and osteoblasts, results in a complete blockage of aggrecan-1, suggesting that Runx2/angiopoitin-1 plays an important role in ectopic calcification [76]. As a upstream regulator of Runx2, promyelotic leukemia zinc finger (PLZF) is upregulated in OPLL cells and facilitates expression of osteoblasts-specific genes in MSCs, thus promoting the ossification of spinal ligament cells in OPLL patients [77]. In addition, Runx2 SNPs, rs1321075 and rs12333172, have been linked to increases in incidence of OPLL and OLF [78]. Runx 2 has been shown to induce hypertrophy of chondrocytes through induction of indian hedgehog (Ihh) [79]. Sugita et al have shown that the MSCs in OPLL tissues have expressions of Ihh, Sox9 and parathyroid-related peptide hormone (PTHrP). Ihh and Sox 9 are highly expressed in proliferating chondrocytes and PTHrP is strongly expressed in hypertrophic chondrocytes. Their expressions are significantly higher in OPLL-derived cells as compared to non-OPLL in culture. These lines of evidence suggest Ihh together with Runx2 and Sox9 regulates chondrocytes differentiation in enchondral ossification process in OPLL [80].

\section{OPLL Biomarkers}

Sclerostin and dickkopf-1(DKK1) are Wnt/ß-catenin signal antagonists that play an important role in bone formation. Sclerostin level reflects age-related changes in bone mass and turnover rate [81]. The secretion of sclerostin increases from individual osteocytes with aging [82]. Deletion of a single allele of the Dkk1 gene leads to an increase in bone formation and bone mass [83]. Serum sclerostin levels in the male OPLL subjects group are significantly higher than those in the control group, which is positively correlated with age and bone mineral density of total hip (TH-BMD). Serum sclerostin and DKK1 levels are negatively correlated in male OPLL subjects. Systemic secretion of sclerostin also increases with advancing age and with higher bone mass in male OPLL subjects [84].

Serum carboxyterminal propeptide of human type 1 procollagen (PICP) and intact osteocalcin are significantly increased in OPLL patients, with a significant correlation to BMD [85]. Serum concentrations of bone formation markers including OCN and PICP show a positive correlation to the OPLL, reflecting the activity of general ectopic bone formation in patients [86]. Serum insulin levels are significantly associated with the extent of OPLL [87]. Serum leptin concentrations corrected for body mass index correlate positively with the number of vertebrae with OPLL involvement in female OPLL subjects, suggesting hyperleptinemia in combination with hyperinsulinemia contributes to the development of heterotopic ossification of the spinal ligament [88].

A proteomic analysis showed carbonic anhydrase I, $\mathrm{NAD}(\mathrm{P})$ dependent steroid dehydrogenase-like, billiverdin reductase $\mathrm{B}$ and alpha-1 collagen VI were down-regulated in OPLL ligaments, while osteoglycin (OGN) and nebulin-related anchoring protein are upregulated in ligaments, as compared to those in non-OPLL ligaments [89]. OGN is known to regulate type I collagen fibrillogenesis via BMP-1 signaling [90]. The detailed functions of these proteins in pathogenesis of OPLL are unknown.

\section{Summary and Future Perspective}

Many attempts have been made to identify both genetic and environmental factors that cause OPLL. The recent GWAS analysis based on large-scale samples have significantly narrowed the functional positions on the chromosomes that may harbor the causal genes of OPLL. However, more efficient methods and statistical analysis are required to identify the target genes from these regions. Although a number of OPLL susceptibility genes have been revealed with appearance of specific SNPs in OPLL specimens for over several decades, most studies are based on small sample sizes and small number of examined sequence variants. Thus, a systematic SNP characterization in OPLL tissues based on large scale samples using whole genome or exome next generation 
sequencing method will be helpful to close this gap. In addition, lack of further functional characterizations of these SNPs makes the genetic association studies insufficient. Whether the SNPs identified to be associated with OPLL are non-functional consequences from the development and progression of OPLL or the causes to the disease remains to be determined.

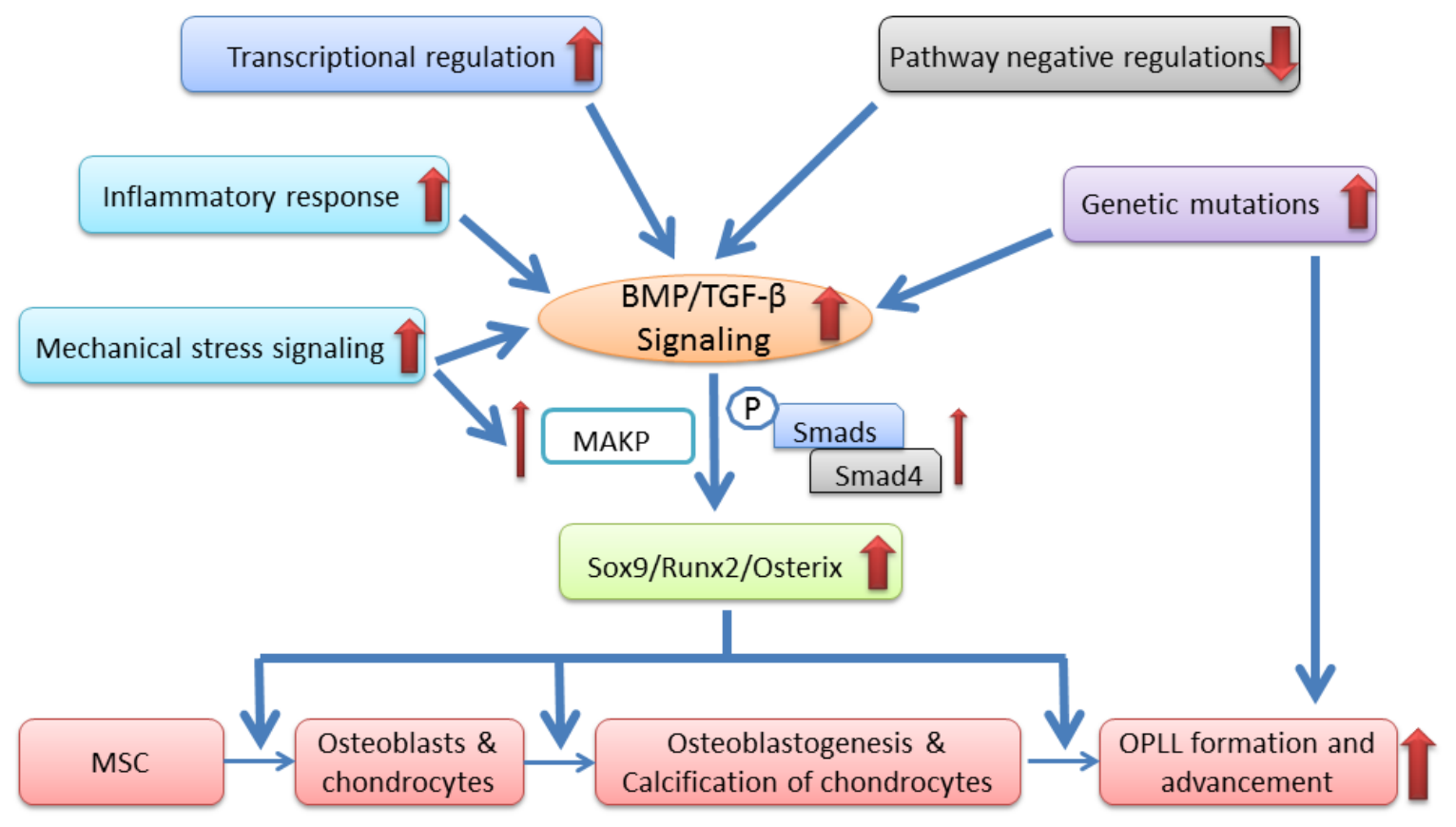

Figure 2. Hypothetic pathogenesis of OPLL. Aberrant activation of BMP and TGF- $\beta$ signaling plays a central role in development of OPLL. Many pathological alterations, including mechanical stress, inflammatory response, transcriptional and pathway negative regulations, and genetic mutations, can cause activation of BMP and TGF- $\beta$ signaling. As a result, Smads/Smad4 and MAPK are upregulated and transcriptions of Sox9, Runx2 and Osterix are increased, which modulates the differentiation and proliferation of MSCs, osteoblasts and chondrocytes and ultimately causes OPLL formation and advancement.

The biochemical and cell biological data on characterizing OPLL-derived MSCs and aberrant signaling pathways such as BMP, TGF- $\beta$ and MAPK have begun to provide new revenues to tackle the question of OPLL pathogenesis. The prominent perivascular locations of MSCs in OPLL tissues suggest MSCs are blood vessel origin which may determine the fate of heterotopic ossification during their differentiation. This line of new evidence has offered fresh insights on the molecular mechanisms underlying OPLL. However, how the aberrant signaling recruits MSCs from pericytes and transits them into heterotopic ossification are the most critical questions yet to be answered, which should be one of the future directions and foci. In summary, we propose that the aberrant activation of BMP and TGF- $\beta$ signaling play a central role in the pathogenesis of OPLL, which can be caused by mechanical stress, radicular pain-induced inflammatory response, transcriptional and pathway negative regulations, and genetic alterations (Fig. 2). Subsequently, the activation of Smads/Smad4 and MAPK upregulates many crucial osteoblastogenic and chondrogenic transcriptional factors, such as Sox 9, Runx2 and Osterix, which results in modulation of differentiation and proliferation of MSCs, osteoblasts and chondrocytes and ultimately causes development and progression of OPLL. Genetic mutations in many genes also directly participate in the pathogenic process of progressive ectopic ossification via BMP/TGF- $\beta$ independent pathways (Fig. 2). 


\section{References}

[1] Key CA (1838). On paraplegia depending on disease of the ligaments of the spine. Guys Hosp. Rep., 3: 17-34

[2] Tsukimoto H (1960). A case report: autopsy of syndrome of compression of spinal cord owing to ossification within spinal canal of cervical spines. Nippon Geka Hokan, 29: 1003-1007

[3] Matsunaga S, Sakou T (2012). Ossification of the posterior longitudinal ligament of the cervical spine: etiology and natural history. Spine, 37: E309-314

[4] Saetia K, Cho D, Lee S, Kim DH, Kim SD (2011). Ossification of the posterior longitudinal ligament: a review. Neurosurgical focus, 30: E1

[5] Kawaguchi Y, Nakano M, Yasuda T, Seki S, Hori T, Kimura T (2013). Ossification of the posterior longitudinal ligament in not only the cervical spine, but also other spinal regions: analysis using multidetector computed tomography of the whole spine. Spine, 38: E1477-1482

[6] Kawaguchi Y, Nakano M, Yasuda T, Seki S, Hori T, Suzuki K, et al. (2016). Characteristics of ossification of the spinal ligament; incidence of ossification of the ligamentum flavum in patients with cervical ossification of the posterior longitudinal ligament - Analysis of the whole spine using multidetector CT. J Orthop Sci, 21: 439-445

[7] Tsuyama N (1984). Ossification of the posterior longitudinal ligament of the spine. Clin Orthop Relat Res: 71-84

[8] Epstein N (2002). Ossification of the cervical posterior longitudinal ligament: a review. Neurosurg focus, 13: ECP1

[9] Yamauchi T, Taketomi E, Matsunaga S, Sakou T (1999). Bone mineral density in patients with ossification of the posterior longitudinal ligament in the cervical spine. $\mathbf{J}$ Bone Miner Metab, 17: 296-300

[10] Stapleton CJ, Pham MH, Attenello FJ, Hsieh PC (2011). Ossification of the posterior longitudinal ligament: genetics and pathophysiology. Neurosurg focus, 30: E6

[11] Yoshimura N, Nagata K, Muraki S, Oka H, Yoshida M, Enyo Y, et al. (2014). Prevalence and progression of radiographic ossification of the posterior longitudinal ligament and associated factors in the Japanese population: a 3-year follow-up of the ROAD study. Osteoporos Int, 25: 1089-1098

[12] Fujimori T, Le H, Hu SS, Chin C, Pekmezci M, Schairer $\mathrm{W}$, et al. (2015). Ossification of the posterior longitudinal ligament of the cervical spine in 3161 patients: a CT-based study. Spine, 40: E394-403

[13] Mori K, Imai S, Kasahara T, Nishizawa K, Mimura T, Matsusue Y (2014). Prevalence, Distribution, and Morphology of Thoracic Ossification of the Posterior Longitudinal Ligament in Japanese: Results of CTBased Cross-sectional Study. Spine, 39: 394-399

[14] Ikegawa S (2014). Genomic study of ossification of the posterior longitudinal ligament of the spine. Proc Jpn Acad Ser B Phys Biol Sci, 90: 405-412

[15] Okazaki T, Takuwa Y, Yamamoto M, Matsumoto T, Igarashi T, Kurokawa T, et al. (1984). Ossification of the paravertebral ligaments: a frequent complication of hypoparathyroidism. Metabolism: clinical and experimental, 33: 710-713

[16] Iwasaki K, Furukawa KI, Tanno M, Kusumi T, Ueyama K, Tanaka M, et al. (2004). Uni-axial cyclic stretch induces Cbfa1 expression in spinal ligament cells derived from patients with ossification of the posterior longitudinal ligament. Calcif Tissue Int, 74: 448-457

[17] Kobashi G, Washio M, Okamoto K, Sasaki S, Yokoyama T, Miyake Y, et al. (2004). High body mass index after age 20 and diabetes mellitus are independent risk factors for ossification of the posterior longitudinal ligament of the spine in Japanese subjects: a case-control study in multiple hospitals. Spine, 29: 1006-1010

[18] Terayama K (1989). Genetic studies on ossification of the posterior longitudinal ligament of the spine. Spine, 14: 1184-1191

[19] Matsunaga S, Yamaguchi M, Hayashi K, Sakou T (1999). Genetic analysis of ossification of the posterior longitudinal ligament. Spine, 24: 937-938; discussion 939

[20] Tanaka T, Ikari K, Furushima K, Okada A, Tanaka H, Furukawa K, et al. (2003). Genomewide linkage and linkage disequilibrium analyses identify COL6A1, on chromosome 21, as the locus for ossification of the posterior longitudinal ligament of the spine. Am J Hum Genet, 73: 812-822

[21] Karasugi T, Nakajima M, Ikari K, Genetic Study Group of Investigation Committee on Ossification of the Spinal L, Tsuji T, Matsumoto M, et al. (2013). A genome-wide sib-pair linkage analysis of ossification of the posterior longitudinal ligament of the spine. J Bone Miner Metab, 31: $136-143$

[22] Nakajima M, Takahashi A, Tsuji T, Karasugi T, Baba H, Uchida K, et al. (2014). A genome-wide association study identifies susceptibility loci for ossification of the posterior longitudinal ligament of the spine. Nature genetics, 46: 1012-1016

[23] Hosoda Y, Yoshimura Y, Higaki S (1981). A new breed of mouse showing multiple osteochondral lesions--twy mouse. Ryumachi. [Rheumatism], 21 Suppl: 157-164

[24] Uchida K, Yayama T, Sugita D, Nakajima H, Rodriguez Guerrero A, Watanabe S, et al. (2012). Initiation and progression of ossification of the posterior longitudinal ligament of the cervical spine in the hereditary spinal hyperostotic mouse (twy/twy). Eur Spine J, 21: 149-155

[25] Okawa A, Nakamura I, Goto S, Moriya H, Nakamura Y, Ikegawa $S$ (1998). Mutation in Npps in a mouse model of ossification of the posterior longitudinal ligament of the spine. Nature genetics, 19: 271-273

[26] Sun Y, Mauerhan DR (2012). Meniscal calcification, pathogenesis and implications. Curr Opin Rheumatol, 24: 152-157

[27] Horikoshi T, Maeda K, Kawaguchi Y, Chiba K, Mori K, Koshizuka Y, et al. (2006). A large-scale genetic association study of ossification of the posterior longitudinal ligament of the spine. Human genetics, 119: 611-616

[28] Koshizuka Y, Kawaguchi H, Ogata N, Ikeda T, Mabuchi A, Seichi A, et al. (2002). Nucleotide pyrophosphatase 
gene polymorphism associated with ossification of the posterior longitudinal ligament of the spine. J Bone Miner Res, 17: 138-144

[29] Tahara M, Aiba A, Yamazaki M, Ikeda Y, Goto S, Moriya H, et al. (2005). The extent of ossification of posterior longitudinal ligament of the spine associated with nucleotide pyrophosphatase gene and leptin receptor gene polymorphisms. Spine, 30: 877-880; discussion 881

[30] He Z, Zhu H, Ding L, Xiao H, Chen D, Xue F (2013). Association of NPP1 polymorphism with postoperative progression of ossification of the posterior longitudinal ligament in Chinese patients. Genetics and molecular research: GMR, 12: 4648-4655

[31] Koga H, Sakou T, Taketomi E, Hayashi K, Numasawa T, Harata S, et al. (1998). Genetic mapping of ossification of the posterior longitudinal ligament of the spine. Am J Hum Genet, 62: 1460-1467

[32] Maeda S, Ishidou Y, Koga H, Taketomi E, Ikari K, Komiya S, et al. (2001). Functional impact of human collagen alpha2(XI) gene polymorphism in pathogenesis of ossification of the posterior longitudinal ligament of the spine. J Bone Miner Res, 16: 948-957

[33] Maeda S, Koga H, Matsunaga S, Numasawa T, Ikari K, Furushima K, et al. (2001). Gender-specific haplotype association of collagen alpha2 (XI) gene in ossification of the posterior longitudinal ligament of the spine. J Hum Genet, 46: 1-4

[34] Sakou T, Matsunaga S, Koga H (2000). Recent progress in the study of pathogenesis of ossification of the posterior longitudinal ligament. J Orthop Sci, 5: 310-315

[35] Kim KH, Kuh SU, Park JY, Lee SJ, Park HS, Chin DK, et al. (2014). Association between BMP-2 and COL6A1 gene polymorphisms with susceptibility to ossification of the posterior longitudinal ligament of the cervical spine in Korean patients and family members. Genet Mol Res, 13: 2240-2247

[36] Kong Q, Ma X, Li F, Guo Z, Qi Q, Li W, et al. (2007). COL6A1 polymorphisms associated with ossification of the ligamentum flavum and ossification of the posterior longitudinal ligament. Spine, 32: 2834-2838

[37] Tsukahara S, Miyazawa N, Akagawa H, Forejtova S, Pavelka K, Tanaka T, et al. (2005). COL6A1, the candidate gene for ossification of the posterior longitudinal ligament, is associated with diffuse idiopathic skeletal hyperostosis in Japanese. Spine, 30: 2321-2324

[38] Wei W, He HL, Chen CY, Zhao Y, Jiang HL, Liu WT, et al. (2014). Whole exome sequencing implicates PTCH1 and COL17A1 genes in ossification of the posterior longitudinal ligament of the cervical spine in Chinese patients. Genet Mol Res, 13: 1794-1804

[39] Chen G, Deng C, Li YP (2012). TGF-beta and BMP signaling in osteoblast differentiation and bone formation. Int J Biol Sci, 8: 272-288

[40] Bonewald LF, Mundy GR (1990). Role of transforming growth factor-beta in bone remodeling. Clin Orthop Relat Res: 261-276
[41] Bonewald LF, Dallas SL (1994). Role of active and latent transforming growth factor beta in bone formation. J Cell Biochem, 55: 350-357

[42] Kamiya M, Harada A, Mizuno M, Iwata H, Yamada Y (2001). Association between a polymorphism of the transforming growth factor-beta1 gene and genetic susceptibility to ossification of the posterior longitudinal ligament in Japanese patients. Spine, 26: 1264-1266

[43] Kawaguchi Y, Furushima K, Sugimori K, Inoue I, Kimura T (2003). Association between polymorphism of the transforming growth factor-betal gene with the radiologic characteristic and ossification of the posterior longitudinal ligament. Spine, 28: 1424-1426

[44] Kawaguchi H, Kurokawa T, Hoshino Y, Kawahara H, Ogata E, Matsumoto T (1992). Immunohistochemical demonstration of bone morphogenetic protein-2 and transforming growth factor-beta in the ossification of the posterior longitudinal ligament of the cervical spine. Spine, 17: S33-36

[45] Han IB, Ropper AE, Jeon YJ, Park HS, Shin DA, Teng YD, et al. (2013). Association of transforming growth factor-beta 1 gene polymorphism with genetic susceptibility to ossification of the posterior longitudinal ligament in Korean patients. Genet Mol Res, 12: 48074816

[46] Jekarl DW, Paek CM, An YJ, Kim YJ, Kim M, Kim Y, et al. (2013). TGFBR2 gene polymorphism is associated with ossification of the posterior longitudinal ligament. J Clin Neurosci, 20: 453-456

[47] Shi S, de Gorter DJ, Hoogaars WM, t Hoen PA, ten Dijke $P$ (2013). Overactive bone morphogenetic protein signaling in heterotopic ossification and Duchenne muscular dystrophy. Cell Mol Life Sc, 70: 407-423

[48] Marcellini S, Henriquez JP, Bertin A (2012). Control of osteogenesis by the canonical Wnt and BMP pathways in vivo: cooperation and antagonism between the canonical Wnt and BMP pathways as cells differentiate from osteochondroprogenitors to osteoblasts and osteocytes. BioEssays, 34: 953-962

[49] Rahman MS, Akhtar N, Jamil HM, Banik RS, Asaduzzaman SM (2015). TGF-beta/BMP signaling and other molecular events: regulation of osteoblastogenesis and bone formation. Bone Res, 3: 15005

[50] Sanchez-Duffhues G, Hiepen C, Knaus P, Ten Dijke P (2015). Bone morphogenetic protein signaling in bone homeostasis. Bone, 80: 43-59

[51] Yonemori K, Imamura $\mathrm{T}$, Ishidou $\mathrm{Y}$, Okano $\mathrm{T}$, Matsunaga S, Yoshida $\mathrm{H}$, et al. (1997). Bone morphogenetic protein receptors and activin receptors are highly expressed in ossified ligament tissues of patients with ossification of the posterior longitudinal ligament. Am J Pathol, 150: 1335-1347

[52] Li JM, Zhang Y, Ren Y, Liu BG, Lin X, Yang J, et al. (2014). Uniaxial cyclic stretch promotes osteogenic differentiation and synthesis of BMP2 in the C3H10T1/2 cells with BMP2 gene variant of rs2273073 (T/G). PloS one, 9: e106598

[53] Wang H, Liu D, Yang Z, Tian B, Li J, Meng X, et al. (2008). Association of bone morphogenetic protein-2 gene polymorphisms with susceptibility to ossification 
of the posterior longitudinal ligament of the spine and its severity in Chinese patients. Eur Spine J, 17: 956-964

[54] Wang H, Yang ZH, Liu DM, Wang L, Meng XL, Tian BP (2008). Association between two polymorphisms of the bone morpho-genetic protein-2 gene with genetic susceptibility to ossification of the posterior longitudinal ligament of the cervical spine and its severity. Chin Med J, 121: 1806-1810

[55] Yan L, Chang Z, Liu Y, Li YB, He BR, Hao DJ (2013). A single nucleotide polymorphism in the human bone morphogenetic protein-2 gene $(109 \mathrm{~T}>\mathrm{G})$ affects the Smad signaling pathway and the predisposition to ossification of the posterior longitudinal ligament of the spine. Chin Med J, 126: 1112-1118

[56] Ren Y, Feng J, Liu ZZ, Wan H, Li JH, Lin X (2012). A new haplotype in BMP4 implicated in ossification of the posterior longitudinal ligament (OPLL) in a Chinese population. J Orthop Res, 30: 748-756

[57] Ren Y, Liu ZZ, Feng J, Wan H, Li JH, Wang H, et al. (2012). Association of a BMP9 haplotype with ossification of the posterior longitudinal ligament (OPLL) in a Chinese population. PloS one, 7: e40587

[58] Furukawa K (2006). Current topics in pharmacological research on bone metabolism: molecular basis of ectopic bone formation induced by mechanical stress. J Pharmacol Sci, 100: 201-204

[59] Iwasawa T, Iwasaki K, Sawada T, Okada A, Ueyama K, Motomura S, et al. (2006). Pathophysiological role of endothelin in ectopic ossification of human spinal ligaments induced by mechanical stress. Calcif Tissue Int, 79: 422-430

[60] Ohishi H, Furukawa K, Iwasaki K, Ueyama K, Okada A, Motomura S, et al. (2003). Role of prostaglandin I2 in the gene expression induced by mechanical stress in spinal ligament cells derived from patients with ossification of the posterior longitudinal ligament. The $\mathrm{J}$ Pharmacol Exp Ther, 305: 818-824

[61] Sawada T, Kishiya M, Kanemaru K, Seya K, Yokoyama T, Ueyama K, et al. (2008). Possible role of extracellular nucleotides in ectopic ossification of human spinal ligaments. J Pharmacol Sci, 106: 152-161

[62] Yang HS, Lu XH, Chen DY, Yuan W, Yang LL, Chen Y, et al. (2011). Mechanical strain induces Cx43 expression in spinal ligament fibroblasts derived from patients presenting ossification of the posterior longitudinal ligament. Eur Spine J y, 20: 1459-1465

[63] Yang HS, Lu XH, Chen DY, Yuan W, Yang LL, He HL, et al. (2011). Upregulated expression of connexin43 in spinal ligament fibroblasts derived from patients presenting ossification of the posterior longitudinal ligament. Spine, 36: 2267-2274

[64] Chen D, Liu Y, Yang H, Chen D, Zhang X, Fermandes JC, et al. (2015). Connexin 43 promotes ossification of the posterior longitudinal ligament through activation of the ERK1/2 and p38 MAPK pathways. Cell and tissue research,

[65] Chen Y, Wang X, Yang H, Miao J, Liu X, Chen D (2014). Upregulated expression of PERK in spinal ligament fibroblasts from the patients with ossification of the posterior longitudinal ligament. Eur Spine J, 23(2):44754

[66] Shapiro F, Cahill C, Malatantis G, Nayak RC (1995). Transmission electron microscopic demonstration of vimentin in rat osteoblast and osteocyte cell bodies and processes using the immunogold technique. Anat Rec, 241: 39-48

[67] Zhang W, Wei P, Chen Y, Yang L, Jiang C, Jiang P, et al. (2014). Down-regulated expression of vimentin induced by mechanical stress in fibroblasts derived from patients with ossification of the posterior longitudinal ligament. Eur Spine J, 23: 2410-2415

[68] He H, Mao L, Xu P, Xi Y, Xu N, Xue M, et al. (2014). Ossification of the posterior longitudinal ligament related genes identification using microarray gene expression profiling and bioinformatics analysis. Gene, 533: 515-519

[69] Medici D, Olsen BR (2012). The role of endothelialmesenchymal transition in heterotopic ossification. J Bone Miner Res, 27: 1619-1622

[70] Nelson ER, Wong VW, Krebsbach PH, Wang SC, Levi B (2012). Heterotopic ossification following burn injury: the role of stem cells. J Burn Care Res, 33: 463-470

[71] Nomura A, Seya K, Yu Z, Daitoku K, Motomura S, Murakami M, et al. (2013). CD34-negative mesenchymal stem-like cells may act as the cellular origin of human aortic valve calcification. Biochem Biophys Res Commun, 440: 780-785

[72] Asari T, Furukawa K, Tanaka S, Kudo H, Mizukami H, Ono A, et al. (2012). Mesenchymal stem cell isolation and characterization from human spinal ligaments. Biochem Biophys Res Commun, 417: 1193-1199

[73] Chin S, Furukawa K, Ono A, Asari T, Harada Y, Wada $\mathrm{K}$, et al. (2013). Immunohistochemical localization of mesenchymal stem cells in ossified human spinal ligaments. Biochem Biophys Res Commun, 436: 698704

[74] Harada Y, Furukawa K, Asari T, Chin S, Ono A, Tanaka $\mathrm{T}$, et al. (2014). Osteogenic lineage commitment of mesenchymal stem cells from patients with ossification of the posterior longitudinal ligament. Biochem Biophys Res Commun, 443: 1014-1020

[75] Nishimura R, Hata K, Matsubara T, Wakabayashi M, Yoneda T (2012). Regulation of bone and cartilage development by network between BMP signalling and transcription factors. J Biochem, 151: 247-254

[76] Kishiya M, Sawada T, Kanemaru K, Kudo H, Numasawa T, Yokoyama T, et al. (2008). A functional RNAi screen for Runx2-regulated genes associated with ectopic bone formation in human spinal ligaments. J Pharmacol Sci, 106: 404-414

[77] Inoue I, Ikeda R, Tsukahara S (2006). Current topics in pharmacological research on bone metabolism: Promyelotic leukemia zinc finger (PLZF) and tumor necrosis factor-alpha-stimulated gene 6 (TSG-6) identified by gene expression analysis play roles in the pathogenesis of ossification of the posterior longitudinal ligament. J Pharmacol Sci, 100: 205-210 
[78] Liu Y, Zhao Y, Chen Y, Shi G, Yuan W (2010). RUNX2 polymorphisms associated with OPLL and OLF in the Han population. Clin Orthop Relat Res, 468: 3333-3341

[79] Yoshida CA, Yamamoto H, Fujita T, Furuichi T, Ito K, Inoue K, et al. (2004). Runx 2 and Runx 3 are essential for chondrocyte maturation, and Runx2 regulates limb growth through induction of Indian hedgehog. Genes Dev, 18: 952-963

[80] Sugita D, Yayama T, Uchida K, Kokubo Y, Nakajima H, Yamagishi A, et al. (2013). Indian hedgehog signaling promotes chondrocyte differentiation in enchondral ossification in human cervical ossification of the posterior longitudinal ligament. Spine, 38: E1388-1396

[81] Szulc P, Boutroy S, Vilayphiou N, Schoppet M, Rauner M, Chapurlat R, et al. (2013). Correlates of bone microarchitectural parameters and serum sclerostin levels in men: the STRAMBO study. J Bone Miner Res, 28: 1760-1770

[82] Modder UI, Clowes JA, Hoey K, Peterson JM, McCready L, Oursler MJ, et al. (2011). Regulation of circulating sclerostin levels by sex steroids in women and in men. J Bone Miner Res, 26: 27-34

[83] Morvan F, Boulukos K, Clement-Lacroix P, Roman Roman S, Suc-Royer I, Vayssiere B, et al. (2006). Deletion of a single allele of the Dkk1 gene leads to an increase in bone formation and bone mass. J Bone Miner Res, 21: 934-945

[84] Kashii M, Matuso Y, Sugiura T, Fujimori T, Nagamoto Y, Makino T, et al. (2016). Circulating sclerostin and dickkopf-1 levels in ossification of the posterior longitudinal ligament of the spine. J Bone Miner Metab, 34(3):315-24

[85] Matsui H, Yudoh K, Tsuji H (1996). Significance of serum levels of type I procollagen peptide and intact osteocalcin and bone mineral density in patients with ossification of the posterior longitudinal ligaments. Calcif Tissue Int, 59: 397-400

[86] Sugimori K, Kawaguchi Y, Ohmori K, Kanamori M, Ishihara H, Kimura T (2003). Significance of bone formation markers in patients with ossification of the posterior longitudinal ligament of the spine. Spine, 28: 378-379

[87] Akune T, Ogata N, Seichi A, Ohnishi I, Nakamura K, Kawaguchi H (2001). Insulin secretory response is positively associated with the extent of ossification of the posterior longitudinal ligament of the spine. J Bone Joint Surg Am, 83-A: 1537-1544

[88] Ikeda Y, Nakajima A, Aiba A, Koda M, Okawa A, Takahashi K, et al. (2011). Association between serum leptin and bone metabolic markers, and the development of heterotopic ossification of the spinal ligament in female patients with ossification of the posterior longitudinal ligament. Eur Spine J, 20: 1450-1458

[89] Zhang Y, Liu B, Shao J, Song J, Zhang J (2015). Proteomic profiling of posterior longitudinal ligament of cervical spine. Int J Clin Exp Med, 8: 5631-5639

[90] Ge G, Seo NS, Liang X, Hopkins DR, Hook M, Greenspan DS (2004). Bone morphogenetic protein1/tolloid-related metalloproteinases process osteoglycin and enhance its ability to regulate collagen fibrillogenesis. J Biol Chem, 279: 41626-41633

[91] Jun JK, Kim SM (2012). Association study of fibroblast growth factor 2 and fibroblast growth factor receptors gene polymorphism in korean ossification of the posterior longitudinal ligament patients. J Korean Neurosurg Soc, 52:7-13.

[92] Meng XL, Wang H, Yang H, Hai Y, Tian BP, Lin X (2010). T allele at site 6007 of bone morphogenetic protein-4 gene increases genetic susceptibility to ossification of the posterior longitudinal ligament in male Chinese Han population. Chin Med J (Engl), 123:2537-42.

[93] Furushima K, Shimo-Onoda K, Maeda S, et al. (2002). Large-scale screening for candidate genes of ossification of the posterior longitudinal ligament of the spine. J Bone Miner Res, 17:128-37.

[94] Chin DK, Han IB, Ropper AE, et al. (2013). Association of VKORC1-1639G>A polymorphism with susceptibility to ossification of the posterior longitudinal ligament of the spine: a Korean study. Acta Neurochir (Wien), 155:1937-42.

[95] Nakamura I, Ikegawa S, Okawa A, et al. (1999). Association of the human NPPS gene with ossification of the posterior longitudinal ligament of the spine (OPLL). Hum Genet, 104:492-7.

[96] Chon J, Hong JH, Kim J, et al. (2014). Association between $\mathrm{BH} 3$ interacting domain death agonist (BID) gene polymorphism and ossification of the posterior longitudinal ligament in Korean population. Mol Biol Rep, 41:895-9.

[97] Kim DH, Jeong YS, Chon J, et al. (2011). Association between interleukin 15 receptor, alpha (IL15RA) polymorphism and Korean patients with ossification of the posterior longitudinal ligament. Cytokine, 55:343-6.

[98] Guo Q, Lv SZ, Wu SW, Tian X, Li ZY (2014). Association between single nucleotide polymorphism of IL15RA gene with susceptibility to ossification of the posterior longitudinal ligament of the spine. J Orthop Surg Res, 9:103.

[99] Chung WS, Nam DH, Jo DJ, Lee JH (2011). Association of toll-like receptor 5 gene polymorphism with susceptibility to ossification of the posterior longitudinal ligament of the spine in korean population. J Korean Neurosurg Soc, 49:8-12.

[100] Yan L, Zhao WG, Li JJ, Yang H, Wang H, Lin X (2010). Linkage of three polymorphisms on chromosome 20p12 to ossification of the posterior longitudinal ligament of spine and its severity in Han Chinese patients. Chin Med J (Engl), 123:2341-6.

[101] Kim DH, Yun DH, Kim HS, et al. (2014). The Insertion/Deletion Polymorphism of Angiotensin I Converting Enzyme Gene is Associated With Ossification of the Posterior Longitudinal Ligament in the Korean Population. Ann Rehabil Med, 38:1-5.

[102] Ogata N, Koshizuka Y, Miura T, et al. (2002). Association of bone metabolism regulatory factor gene polymorphisms with susceptibility to ossification of the posterior longitudinal ligament of the spine and its severity. Spine, 27:1765-71. 
[103] Kim KT, Lee SH, Kwack YH (2012). Association of Estrogen Receptor 2(ESR 2) Gene Polymorphisms with Ossification of the Posterior Longitudinal Ligament of the Spine. J Korean Soc Spine Surg, 19:1-7.

[104] Numasawa T, Koga H, Ueyama K, et al. (1999). Human retinoic $\mathrm{X}$ receptor beta: complete genomic sequence and mutation search for ossification of posterior longitudinal ligament of the spine. J Bone Miner Res. 14:500-8.
[105] Kobashi G, Ohta K, Washio M, et al. (2008). FokI variant of vitamin $\mathrm{D}$ receptor gene and factors related to atherosclerosis associated with ossification of the posterior longitudinal ligament of the spine: a multihospital case-control study. Spine, 33:E553-8. 